\title{
The Semantic Field Theoretical Approach in the teaching of English and its Grammatical Implication to Second Language Development
}

\author{
Benard Angatia Mudogo \\ Lecturer, Masinde Muliro University of Science \& Technology, Kenya \\ $\square$ Corresponding Author: Benard Angatia Mudogo, E-mail: dmudogo@mmust.ac.ke
}

\section{ARTICLE INFORMATION}

Received: December 08, 2020

Accepted: February 28, 2021

Volume: 3

Issue: 3

DOI: 10.32996/ijels.2021.3.3.1

\section{KEYWORDS}

Lukabarasi, Preschool Learners, Semantic Field Theory, Songs,

Syntactic Constraints

\section{ABSTRACT}

The Semantic Field Theory (SFT) has been widely used in teaching English as a second Language to preschool children in Kenya. In the SFT approach, the grammars of two or more languages are in contact. The grammar of languages involved in the SFT approach may be similar or different. However, studies have indicated that where the grammar of two languages in contact differ, syntactic mismatches are likely to result. It was against this background that the investigation was undertaken to establish the potential syntactic mismatches between English and Lukabarasi when using the SMT approach and the possible grammatical implications to English language development lessons. Contrastive Analysis (CA) by Lado (1967) was used in the comparison of the structures of Lukabarasi and English in order to identify syntactic similarities and differences in The First Language (L1) and The Second Language (L2). A sample of 10 key informants teaching English as a second language in rural preschools were purposively sampled to help collect the songs. Two songs were purposively sampled for collecting the relevant data. Content analysis guided the data analysis to identify the parts of the songs that were relevant to the achievement of the research objective. The findings indicated that teachers used Lukabarasi songs during English development lessons to enhance vocabulary acquisition using the SFT approach. Further, rules of the two languages were not observed and finally, there were syntactic mismatches during the teaching of English lessons. The findings revealed that extensive use the SMT approach and failure to follow rules of languages during L2 lessons may affect second language development. The findings recommend use of SFT approach when necessary in teaching English and adherence to rules of the two languages during English lessons to reduce negative transfer and to enhance L2 development.

\section{Introduction}

The Semantic Field Theory (SFT) has been widely used in teaching English as a second Language to preschool children in Kenya. The proponents of the SFT argue that teaching second language vocabulary using semantic fields is an effective method of vocabulary instruction (Aitchison, (1994) Carter \& McCarthy, (1989); Lewis, (1997). However, linguists are in agreement that each language has its grammar that guides its users. Therefore, in evaluating the grammatical implications of using the SMT approach in teaching English, there is a need to interrogate the syntax of the two languages used in the process of language teaching.

Furthermore, the most important component of grammar of any language is its syntax. This is because syntax forms the heart of sentence structure and the rules of semantics and phonological components are taken to be an interpretation of the syntactic structure ((Mwangi, Kinyanjui, Gecaga, Indangasi \& Mukunga, 2009)) Therefore, to understand the grammatical aspects used in the SMT process, it was necessary to pay attention to the grammar of the two languages used in the learning process. The investigation would reveal the grammatical implication of using Lukabarasi songs to teach English vocabulary to pre-school

K C AL-KINDI CENTER $R$ FOR RESEARCH AND $R$ D DEVELOPMENT Your gateway to world-class research

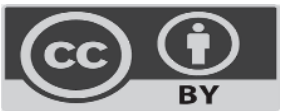

Published by Al-Kindi Center for Research and Development. Copyright (c) the author(s). This open access article is distributed under a Creative Commons Attribution (CC-BY) 4.0 license 
children in selected early childhood leaning centers in Kakamega North Sub County, Western Kenya. The focus was on how the syntax of the two languages incorporated in selected songs impacted on the acquisition of English during the SMT lessons.

\section{The Semantic Field Theory}

The Semantic Field theory (SFT) was developed by German scholar J. Trier in the 1930s, in the field of lexical semantics (Guo, 2010). The proponents of the SFT argue that teaching second language vocabulary using semantic fields is an effective method of vocabulary instruction (Aitchison, 1994; Gathigia, 2018). According to Gao and Xu (2013: 2031), a semantic field is a grouping of words that 'interact, dominate, distinguish and depend on each other'. The advocates of the SFT claim that the theory is in compliance with brain theories which suggest that there is a good organization of semantic fields in the human brain (Aitchison, 1994).

As observed by Gathigia (2018, p. 299) the SFT 'discourages the conceptualization of a lexicon as a mere aggregation of idiosyncratic items by helping the learners' to enlarge their vocabulary in constructing paradigmatic relations of new items and deepens the mastery of vocabulary by constructing syntagmatic relations of the new items'. In this respect, Gathigia (ibid, p. 299) for instance proposes the application of the SFT in the teaching of English as a second language, arguing that teachers should, therefore, 'pick out words belonging to the same semantic field in addressing the question of learning semantically related words in a coherent manner'. According to him SFT should be applied because vocabulary is problematic to teach and, difficult for second language learners to comprehend due to the complexity of some word forms. For the present investigation, there was a need to pay attention to the grammatical implication of using the SMT approach in teaching of English. This is because the grammar of languages involved in the SMT approach may be similar or different. However, scholars such as Appel and Muysken (2005) have revealed that where two languages' grammar differs, syntactic constraints are likely to result. Therefore, an appropriate approach should not be used at the expense of the target language but rather facilitate the learning of L2.

\section{Theoretical Framework}

Contrastive analysis (CA) by Lado (1967) guided the study in identifying the comparison of elements of the two languages involved in order to identify similarities and differences in L1 and L2. The differences between the word order of Lukabarasi and English were used to analyze predict possible grammatical implication in the teaching of L2. Croft (2003) notes that studies on language structure have shown that although languages may have similarities, they could also differ from each other in many unpredictable ways. In view of the existence of both similarities and differences in languages, there is need to study the language structures of different languages especially in the bilingual world. The comparison is necessary in bilingual education where the role of L1 in target language learning has been identified.

\section{Research Methodology}

A survey research design was adopted because the focus was on collecting Lukabarasi songs that could highlight the applicability of the Semantic Field theory in teaching of English. A survey research design is defined as 'the collection of information from a sample of individuals through their responses to questions' (Check \& Schutt, 2012, p. 160). Therefore, 10 Key informants who teach language to preschools in rural primary schools were sampled to help in the collection of songs. After six Lukabarasi songs were collected through tape-recording, purposive sampling was employed to selected two songs for analysis. The songs were; 'Omwalimu wefu teacher' (Our teacher) and 'Vuli suvui morning' (Every morning). Audio recording of data on classroom discourse between teachers and learners during English lessons was also done. The collected data was transcribed to enable the researcher get information on grammatical comparison between English and Lukabarasi. Using clauses with EnglishLukabarasi constituents from the transcribed data, the researcher was able to identify the elements of syntactic mismatches between two languages, as well as analyze the syntactic constraints during SMT lessons.

Content analysis, which is within the qualitative research paradigm (Creswell, 2008), guided the analysis of the songs in order to identify the parts of the songs that were relevant to the achievement of the research objective. Researchers regard content analysis as a flexible method for analyzing text data (Cavanagh, 1997; Rosengren, 1981). The choice of content analysis was also premised on the fact that it goes beyond merely establishing the correlation between the meanings of words in the two languages involved in as may be manifested in a particular text (Patton, 2002). The researcher, therefore, did a line-by-line syntactic comparison of the L1 and L2 versions of the songs to evaluate the grammatical implications in the teaching of L2

\section{Discussion of Key findings}

Teachers were using Lukabarasi songs to introduce new English words and also to correct learners. Syntactic rules of both English and Lukabarasi were not given much attention. This may be because of the assumption that these rules were not 
necessary in learning new words. Therefore, the focus was placed on an understanding of the concepts at the expense of the packaging of the information. Further, a close look at some of the texts retrieved from the recorded data revealed that almost 80 percent of the words used were in Lukabarasi. An analysis of the recorded data, confirmed that teachers used Lukabarasi extensively. Teachers over reliance on Lukabarasi disadvantages the learning of English grammar. The findings were similar to those of Chamber (1991) who established that in some cases, teachers and learners engaged unnecessary L1 use which threatened the learners' optimal learning of the target language. As observed by Celik (2008), the use of using two languages has positive impacts, but it should be used with caution to avoid disadvantaging the target language. In the current paper, English is the target language. It is therefore expected that the syntactic arrangement in the songs should follow the surface order of the English language and the ones that did not follow were used to explain the syntactic constraints. The paper used two Lukabarasi songs below, Omwalimu wefu teacher, 'Our teacher' and Vuli suvui morning, 'Every morning', to illustrate the grammatical implications of the songs in the teaching.

\section{Song 1: Omwalimu wefu 'teacher' Lukabarasi \\ Omwalimu wefu 'teacher' \\ Wukholile vulei sana 'very well' \\ Okhwechesia avana 'children' \\ Okukhumanya okhusoma 'reading' \\ Asanti omwalinu omulei 'good teacher' \\ Musukulu yalava yino 'smart'}

\author{
(Our teacher) \\ English gloss \\ Our teacher \\ You have done very well \\ To teach the children \\ To know reading \\ Thank you good teacher \\ In this smart school
}

\section{Song 2: Vuli suvui morning Lukabarasi \\ Vuli suvui 'morning' \\ Esie esavanga mumoni 'face' \\ Enywa echai yanche 'tea' \\ Esukue ameno kanche 'teeth' \\ Enchenula liswi lianche ' hair' \\ Nenzia shesuukulu 'school' \\ Thisuku tsirano five \\ Kwisitsa lilala week

\author{
(Every morning). \\ English gloss \\ Every morning \\ I wash my face \\ I drink my tea \\ I brush my teeth \\ I comb my hair \\ I go to school \\ In one week
} \\ Five days}

The two songs presented above were used in the teaching of English vocabulary. However, although some English lexical items are introduced to the learners, attention should be paid to the syntactic mismatches between Lukabarasi and English. Bantu languages, for instance, are characteristically distinct. An instructor, working with any language, needs to be critically aware of its distinguishing typological properties. Although Gathigia (2018) observes that the use of semantic relations as in the songs above can help the learners integrate the lexical items into a larger semantic field of the context of use, attention must be paid to Ulrich (2004) observations that should there be dissimilarities between the two languages in contact, ungrammatical utterances will be evident. Such utterances are caused by what Ulrich (ibid) calls equivalence constraint which assumes that languages in contact share the same categories and do not envisage the categories in the two languages mismatching because of typological dissimilarities. For the present investigation, there was a need to correlate the grammars of the two languages and evaluate their impact on L2 learning. Consequently, the following grammatical mismatches discussed below emerged;

\subsection{Demonstratives}

Within the NP, the English demonstrative is used before the noun head while in Lukabarasi it can be used either before or after the head noun as shown in example 1 below;

\section{Example 1 \\ i. Lukabarasi: Musukulu yalava yino \\ ii. English: In this smart school}

In example 1, the English demonstrative 'this' and 'yino'(this) in Lukabarasi occur in different sections of the NP. The grammatical mismatch here is caused by the fact that the order of the English and Lukabarasi demonstratives in an NP is different. Data from classroom discourse showed that the learners used demonstratives after noun heads as in example 2 below; 


\section{Example 2}

Learner 1: *Teacher this of our is good

Therefore, the using of the demonstrative after the NP by Learner 1 above violates the English NP order which may be attributed to syntactic constraints in L2 acquisition. Example 2 above gravitates to Nemser's (1971) assertions that when mastering a target language, L2 learners may acquire a linguistic system that is self-contained and different from both the learner's L1 and the target language. Such faulty acquisition may be caused by influence from their L1.

\subsection{Possessive Constraints}

Possessives are used to specify the Noun head in a NP. In an English NP, the possessive is used before the Noun head, while in Lukabarasi, the possessive is used before the NP as shown in Example 3 below.

\section{Example 3}

i. Lukabarasi: Mwalimu wefu teacher

ii. English: Our teacher

Considering example 3 (i) and (ii), the possessive in English is used attributively while in Lukabarasi, it is used predicatively in relation to the noun head. Using data from classroom discourse, it also emerges that learners used possessives predicatively as observed from the example by Learner 1 above. Wambugu et all (2018) attributes errors in L2 learning partly to teachers' inadequacy in second language pedagogy. In this respect, lack of attention to $L 2$ syntactic rules during the teaching process was observed to contribute to learners' errors.

\subsection{Adjective Constraint}

The English adjective is positioned before the noun head in a noun phrase. The position of adjective in English contrasts with the Lukabarasi adjective because its adjective is placed after the noun head as illustrated in example 4;

\section{Example 4}

i. Lukabarasi: Omwalimu omulei

ii. English: Good teacher

The collected data revealed that learners resorted to their first language syntactic rules when forming English sentences. For instance, adjectives were placed after nouns as illustrated by the utterance from learner example 5 below;

\section{Example 5}

Learner 2: *Teacher good very is Nancy

In example 5 above, the syntactic differences between English and Lukabarasi triggered the ungrammatical utterance by Learner 2. Besides, Mwangi et al. (2009) suggest that to understand the grammar of a language, it is necessary to understand rules that human beings employ to join words into meaningful structures. For the present case, the extensive use of the SMT approach was observed to impede the grammatical development of the target language.

\subsection{Adverb Constraints}

Adverbs in English like Lukabarasi can occupy different positions in a sentence. The ability to be in different positions is crucial in the teaching of L2. Therefore, when an adverb is used to modify other words like adjectives and quantifiers, attention must be paid to the word order of the two languages involved. For instance, adverb precedes adjectives and quantifiers in English, while in Lukabarasi it is used after as shown in the song extract in example 6 below;

\section{Example 6}

i. Lukabarasi: Mulei sana

ii. English: Very good

In example 6 above, a different position taken by the adverbs 'very' in 6 (i) and 'sana' (very) in 4 (ii) would create a constraint in L2 learning. In this respect, the sentence by Learner 2 violates the English word order that requires the adverbs to precede the quantifiers, thus leading to an ill formed structure.

\subsection{Numerals}

Numerals indicate the figures in a noun phrase. Numerals in English are used before the noun head. However, in Lukabarasi, they come after the noun head as in Example 7 below; 


\section{Example 7}

i. Lukabarasi: Tsissuku tsirano five

ii. English: Five days

There is a constraint because number in English is used before the noun head while in Lukabarasi it is used after. Therefore, the English number contrasts with number in Lukabarasi whose morphological order is different.

\subsection{Personal Pronouns}

English and Lukabarasi Personal pronouns were observed to have different rules in terms of usage and word formation.

\section{Example 8}

i. Lukabarasi: Esie esavanga mumoni

ii. English: I wash my face

Example 8 (i) shows that Lukabarasi allows the duplication of personal pronouns in a sentence since 'esie' and the subject personal prefix ' $e-{ }^{-}$are used in the same sentence. In contrast, English allows one personal pronoun to be used as a subject in a sentence as shown in example 8 (ii). From the collated data, it was revealed that the learners used Lukabarasi syntactic structures in the construction of English sentences as shown in Example 9 below;

\section{Example 9}

Learner 3: * Me I go to school.

Example 9 shows ungrammatical construction by learner 3 which violates the English sentence order.

The data also revealed that English and Lukabarasi grammar had both similarities and differences in syntactic rules of elements during the SFT approach. For instance, in the third line of the Song 1, where the syntactic order has the same syntactic order as English as shown example 10 below;

\section{Example 10}

Lukabarasi: okhumanya khusoma reading'

English: to know reading

The similarities in the syntactic rules as shown in example 9 above would help learners learn the new items as well as construct paradigmatic relations between Lukabarasi and English items.

\section{Conclusion}

From the findings and discussion of this paper, certain conclusions are drawn. First, it concludes that although SFT is a good teaching strategy, its extensive use and failure to follow rules of the languages involved has negative grammatical implications in the teaching of English in Kenyan schools. The paper therefore makes several recommendations. Firstly, teachers should use the target language during the lesson and SFT be used only when necessary. Secondly, the rules of the language involved in SFT should be observed during second language teaching. Thirdly, syntactic mismatches of the languages used during SFT should be identified since they may be used to expose learners to the differences in the languages involved. Such knowledge may not only enhance the second language development but also prevent a possible L1 to L2 negative transfer. This investigation, therefore, strengthens previous research findings about error transfer in teaching of second language to learners. However, it is important to note that this paper was very limited regarding the number of participants and the number of songs under study. 


\section{References}

[1] Aitchison, J. (1994) Words in the mind: An introduction to the mental lexicon. Oxford: Blackwell.

[2] Appel, R., \& Muysken, P. (2005) Language contact and bilingualism. Edward Arnold: Amsterdam University Press.

[3] Carter, R., \& McCarthy, M. (Eds.) (1989) Vocabulary and language teaching. New York: Longman.

[4] Cavanagh, S. (1997) Content analysis: Concepts, methods and applications. Nurse Researcher, 4, 5-16.

[5] Celik, S. (2008) Opening the door: An examination of mother tongue use in foreign languages classroom. Hacetteppe University Journal of Education 34, 75-85.

[6] Chambers, F. (1991) Promoting use of target language in the classroom. Language Learning Journal, 4, $27-31$.

[7] Check, J., \& Schutt, R. K. (2012) Survey research. In J. Check \& R. K. Schutt (Eds.) Research methods in education (pp.159-185). Thousand Oaks, CA: Sage Publications.

[8] Creswell, J. W. (2008) Educational research: Planning, conducting, and evaluating quantitative and qualitative research (3rd Edition). Upper Saddle River, NJ: Pearson Education, Inc.

[9] Croft,W. (2003) Typology and universals. Cambridge University: Cambridge University Press.

[10] Gathigia, M, G (2018). Vocabulary Instruction in Kenyan Pre-Schools: A Semantic Field Theoretical Approach. Coretrain Journal of Languages, Humanities, Social Sciences and Education. 1, 298-304

[11] Guo, C. (2010) The application of the semantic field theory in College English vocabulary instruction. Chinese Journal of Applied Linguistics, $33,50-62$.

[12] Lado, R. (1967) Linguistics across cultures. An Arbor: University of Michigan Press.

[13] Lewis, M. (1997) Implementing the lexical approach: Putting theory into practice. London: Language Teaching Publications.

[14] Patton, M. Q. (2002) Qualitative research and evaluation methods. Thousand Oaks, CA: Sage.

[15] Ulrich, A. (2004) Sociolinguistics. An interaction handbook of language and society. New York: Walter de Gruyter.

[16] Rosengren, K. E. (1981) Advances in Scandinavia content analysis: An introduction. In K. E. Rosengren (Ed.) Advances in content analysis. Beverly Hills, CA: Sage. 9-19. 